\title{
Endothelial Cells and Vasculitis
}

\author{
Vidosava B. Djordjević, Vladan Ćosić, Lilika Zvezdanović-Čelebić, \\ Vladimir V. Djordjević and Predrag Vlahović \\ University of Niš, School of Medicine/Clinical Centre Niš
}

Serbia

\section{Introduction}

The vascular endothelium is a specific organ consisting of the endothelial cell (EC) monolayer, weighting about $1 \mathrm{~kg}$ which makes a unique border between the circulating blood and the underlying tissues. Because of its strategic location, the endothelium interacts with cellular and neurohumoral mediators, thus controlling the vascular contractile state and cellular composition. Endothelial cells (ECs) used to be considered a layer of "nucleated cellophane", an inert lining to blood vessels, endowed with negative properties, and the most important of which is its ability to act as a non-thrombogenic substrate for blood. Further, the endothelium was thought to participate in tissue reactions as target for injurious agents. Now the endothelium is recognized as a semipermeable barrier that regulates the transfer of small and large molecules, a highly specialized, metabolically active organ having vital metabolic, secretory, synthetic and immunologic functions. It performs significant autocrine, paracrine and endocrine actions and exerts influences on smooth muscle cells, platelets and peripheral leucocytes. Therefore, haemostasis, inflammatory reactions and immunity involve close interactions between immunocompetent cells and vascular endothelium.

ECs arise from hemangioblasts, blast-like bipotential cells (Choi et al., 1998). They can also transdifferentiate into mesenchymal cells and intimal smooth muscle cells. It is known that there is a marked phenotypic variation between ECs in different parts of the vascular system. The cells from different location in the same person not only express different surface antigens and receptors, but can generate different responses to the same stimulus. Further, cells from the same part of the vasculature can have varied responses (Galley \& Webster, 2004).

The vascular endothelium senses mechanical stimuli, such as pressure and shear stress, and hormonal stimuli, such as vasoactive substances. In respons, it releases agents that regulate vasomotor function, trigger inflammatory processes and affect hemostasis. Among the vasodilatory substances the endothelium produces are nitric oxide (NO), prostacyclin, different endothelium derived hyperpolarizing factors and C-type natriuretic peptide. Vasoconstricting molecules include endothelin-1 (ET-1), angiotensin II (Ang II), thromboxane $\mathrm{A}_{2}$ and reactive oxygen species (ROS) (Endemann \& Schiffrin, 2004). Inflammatory modulators include NO, intercellular adhesion molecule-1 (ICAM-1), vascular adhesion molecule-1 (VCAM-1), E-selectin, and NF-kB. The endothelium realizes the modulation of hemostasis by releasing: plasminogen activator, tissue factor inhibitor, von 
Willebrand factor, $\mathrm{NO}$, prostacyclin, thromboxane $\mathrm{A}_{2}$, plasminogen/activator, inhibitor/1 and fibrinogen. The endothelium also contributes to mitogenesis, angiogenesis, vascular permeability and fluid balance. The endothelium is indispensable for body homeostasis. An controlled endothelium cell response is involved in many disease processes including atherosclerosis, hypertension, pulmonary hypertension, sepsis and inflammatory syndromes including vasculitis. These diseases are related to endothelial injury, dysfunction and activation.

\section{Physiological functions of endothelial cell}

In order for ECs to perform their physiological functions, they should exist in the so-called resting or quiescent state. It seems that, under normal resting conditions, ECs constitutively express certain "protective" genes, such as that encoding Bcl- $\mathrm{x}_{\mathrm{L}}$, the purpose of which is to maintain ECs in their quiescent phenotype by inhibiting nuclear factor $\mathrm{KB}(\mathrm{NFKB})$ activation and exerting anti-apoptotic functions (Bach et al., 1997). In this state ECs can perform their normal barrier and anticoagulant functions even in the presence of low levels of stimulans, such as shear stress, circulating endotoxins or reactive oxygen species. In the quiescent state, the antithrombotic, anti-inflammatory and antiproliferative properties of the endothelium are maintained by the dominance of nitric oxide (NO) signaling and the formation of S-NO modifications of proteins, shear stress signaling through the surface glycocalyx and signaling between pericytes and the endothelium.

\subsection{Transport functions}

ECs makes an important barrier to the free passage of molecules and cells from the blood to the underlying interstitium and cells. Transport functions are realized by protein transporters, caveolae and tight junctions. Specific transport mechanisms transport essential circulating macromolecules across ECs to the subendothelial space to enable the metabolic needs of the surrounding tissue cells. ECs express glucose transporters GLUT-1 and GLUT4. GLUT-1 is the most abundant endothelial isoform. The blood-brain barrier is the major endothelial tissue expressing GLUT transporters, although these transporters have been also detected in other ECs including the umbilical vein, adrenal capillaries, aorta, retina, heart, placenta, the eye and testis (Mann et al., 2003).

Aminoacids are transported by multiple transport systems in ECs, but the system $\mathrm{y}^{+}$catonic amino acid transporter is perhaps most relevant, since this system transports L-arginine, the substrate for nitric oxide. Cytokines such as TNF $\alpha$ can stimulate L-arginine transport in ECs resulting in increased NO production (Bogle et al., 1995).

Transcellular transport in ECs occurs via caveolae which represent invaginations in the cell membrane and which are primary important in albumin transport across the endothelium. Albumin binding proteins (albumin binding glycoprotein, gp60) initiate the endocytosis of albumin by associating with the scaffolding protein caveolin-1 and activating the kinase Src. The Src enzyme phosphorylates caveolin-1 and a second protein dynamin (Galley \& Webster, 2004). This results in the fission of caveolae and internalization of albumin. In the endothelium, caveolin-1 regulates nitric oxide signaling by binding to and maintaining endothelial nitric oxide synthase (NOS) in an inactive state (Bucci et al., 2000). Caveolin-1 is also an important determinant of calcium signaling in ECs because calcium influx channels and pumps are localized in caveolae (Fujimoto, 1993). 
Paracellular transport is realized through tight junctions. Within multicellular organisms, several organs are relatively independent of whole body homeostasis and are wrapped by EC sheets. For example, the blood brain barrier is made of highly specialized ECs whose tight junctions protect the central nervous system. Tight junctions can function as either a "gate" (selected passage of molecules) or a "fence" (no passage) (Sawada et al., 2003). The gate function regulates the passage of ions, water and various macromolecules, even of cancer cells, through paracellular spaces. This type of function is important in oedema, jaundice, diarrhoea and blood-borne metastasis. The fence function maintains cell polarity by preventing the mixing of molecules in the apical EC membrane with those in the lateral membrane. Some pathogenic bacteria and viruses target and affect the tight junction function, leading to diseases affecting the vascular system (oedema), the gastrointestinal tract (bacterial enteritides) and respiratory tract (acute respiratory distress syndrome) (Galley \& Webster, 2004).

\subsection{Vascular tone regulation}

The endothelium produces a number of vasodilator and vasoconstrictor substances which regulate vasomotor tone, but the most important is NO.

\subsubsection{Nitric oxide}

Nitric oxide is the most powerful vasodilator. Resting ECs constitutively express an endothelial specific isoform of nitric oxide synthase (eNOS, NOS3) which synthesizes NO from L-arginine (Palmer et al., 1988) maintaing the vasculature in a state of vasodilatation. The most important stimuli are physical factors such as shear stress and pulsatil stretching of the vessel wall as well as circulating and locally released vasoactive substances. The endothelium can be taken as a biosensor reacting to a large variety of stimuli and therefore maintaing an adequate NO release. ECs can express both, Ca-dependent constitutive NOS and $\mathrm{Ca}^{2+}$-independent inducible NOS (iNOS, NOS2). In unstimulated ECs, eNOS is targeted to specific microdomains in the plasma membrane called caveolae, where eNOS is associated with a scaffold protein caveolin, resulting in the tonic inhibition of the enzyme activity (Garcia-Cardena et al., 1997; Michel et al., 1997). The elevation of $\mathrm{Ca}^{2+}$ induced by $\mathrm{Ca}^{2+}$-elevating agonists stimulates the binding of calmodulin to eNOS challenging the dissociation of the enzyme from caveolin and thereby its activation (Michel et al., 1997). Some stimuli such as shear stress and ceramide can induce the $\mathrm{Ca}^{2+}$-independent activation of eNOS (Igarashi et al., 1999). Shear stress and receptor agonists (such as bradykinin and vascular endothelial growth factor) can induce the phosphorylation of eNOS by Akt and its translocation to the cytosol where it interacts with calmodulin and the chaperone Hsp90. There is evidence that the some situations are associated with an increased activity and the amount of constitutive eNOS indicating that this isoform can also be induced. Although caveolae play an integral part in regulating the activity of eNOS, proinflammatory cytokines also increase the activity of GTP-cyclohydrolase, the rate-limiting enzyme for tetrahydrobiopterin production, which is a cofactor for NOS (Harrison, 1997). The $y^{+}$amino acid transporter channels are co-located with NOS on caveolae, and the recirculation of Larginine from L-citruline mediated by cytokines occurring in vascular ECs (Lee \& Yu, 2002) makes substrate for NO production available. NO is subsequently produced by the enzyme only when the substrate L-arginine and the cofactor tetrahydrobiopterine are available. NO can then react with the cysteine motifs in proteins throughout ECs to make S-NO 
modifications to these proteins (S-nitrosylation), thereby silencing multiple metabolic processes, including apoptotic cell death regulation (Mannick, 2007) and the inhibition of mitochondrial oxidative phosphorylation during hypoxia or a protection against hypoxia by increasing the binding activity of hypoxia-inducible factor $1 \alpha$. S-nitrosylation of NF-kB can suppress inflammation (Rabelink \& Luscher, 2006). L-arginine depletion occurs when it is diverted into alternative metabolic pathways through the redox induction of enzymes such as arginase and protein methyltransferases.

Under prolonged redox signaling, eNOS itself may switch from being an enzyme that produces NO into the one that produces reactive oxygen species. This event is known as NOS "uncoupling", and it is dependent on the lack of availability of the cofactor tetrahydrobiopterine, which is essential for the eNOS-dependent production of NO. The amount of tetrahydrobipterin can be reduced as a result of direct oxidation by ROS derived from another source followed by the amplification of oxidative stress or when hydrogen peroxide induces the inactivation of the enzymes GTP-cyclohydrolase and dihydrofolate reductase, which generate and regenerate tetrahydrobiopterine. When its levels are low the heme group in eNOS will directly yield superoxide and hydrogen peroxide (Crabtree et al., 2009). The enzyme may reduce molecular oxygen rather than transfer electrons to Larginine, thereby generating superoxide. Superoxide is believed to originate from the oxygenase domain of the enzyme through the dissociation of a ferrous-dioxygen complex that is normally stabilized by tetrahydrobiopterine (Xia et al., 1998). This uncoupling converts eNOS into an accelerator of redox signaling followed by the production of large amounts of ROS inducing a proinflammatory state (Rabelink \& Luscher, 2006). Several enzymes such as the hemoxygenase system (Ryter et al., 2006), antioxidant enzymes, thioredoxin reductase and glutathione reductase (Hojo et al., 2002) can scavenge ROS and "fine-tune" this activation cascade, to the extent that ROS exceed the antioxidative capacity of cellular antioxidants (Cai \& Harrison, 2000). This process explains how the chronic activation of the endothelium or impaired activity of eNOS can lead to the endothelial dysfunction.

Endothelial iNOS may be induced in both physiological and pathological conditions. Known physiological settings include pregnancy, treatment with oestradiol (Weiner et al 1994), shear stress, chronic exercise or receptor agonists (such as bradykinine and vascular endothelial growth factor). In activated ECs iNOS can be induced producing much higher levels of NO then those present under physiological conditions and that is implicated in the pathogenesis of a wide variety of diseases involving endothelium (Djordjević et al., 2004; Djordjević et al., 2008). iNOS is highly regulated by cytokines, some of which promote while others inhibit the enzyme induction. Although there are indices suggesting that a cocktail of three cytokines (TNF- $\alpha$, IL-1 $\beta$ and IFN- $\gamma$ ) (Steiner et al., 1997), is neccesery for NOS induction, most data showed that NOS induction can be triggered by a mixture of two cytokines especially IL-1 and TNF (Mantovani et al., 1997). Transforming growth factor $-\beta$ (TGF- $\beta$ ) reduces cytokine-induced iNOS activity by inhibiting iNOS mRNA translation and increasing iNOS protein degradation, while IL-4 interferes with iNOS transcription (Bogdan et al., 1991). The disruption of genes encoding IFN- $\gamma$, part of its receptor or an IFN regulatory factor results in a phenotypic deficiency in iNOS expression. EC produced NO may exert an autocrine function. It inhibits the cytokine-induced expression of adhesion molecules and cytokine production by ECs through inducing and stabilizing of NF-kB inhibitor (Peng et al., 1995), thus attenuating proinflammatory responses. 


\subsubsection{NADPH oxidase}

An emerging paradigm in vascular homeostasis involves the balance between ROSmediated and NO-mediated signals. ROS contribute to cellular signaling, affecting almost all aspects of cellular function including gene expression, proliferation, migration and cell death. It is now clear that ROS play an important role in regulating the normal function of the endothelium. However, the generation of ROS both within ECs and in adjacent cells such as vascular smooth muscle cells, adventitial fibroblasts and inflammatory cells has a major role in the genesis of endothelial activation and dysfunction. The potential sources of superoxide in ECs include the mitochondrial electron transport chain, xanthine oxidase, cytochrome p450 enzymes, uncoupled NOS and NADPH oxidases. Mitochondria are both a source and a target for ROS. Because they are susceptible to oxidative damage it can result in enhanced mitochondrial ROS production (Cai \& Harrison, 2000). Xanthine oxidase is expressed on the luminal surface of the endothelium and catalyses the conversion of hypoxanthine into urate in the process that generates superoxide. An increased xanthineoxidase-derived superoxide production is involved in endothelial dysfunction in several diseases.

NADPH oxidase is considered as a rather special source of ROS generation since its the primary function is the regulation of ROS production, primarily identified and characterized in phagocytes where it plays an essential role in host defense against microbial organisms. Furthermore it has become apparent that ROS production by NADPH oxidase homologues in non-phagocytic cells also plays an important role in the regulation of signal transduction via the modulation of kinase and phosphatase activities or through gene transcription (Finkel, 2003; Groemping \& Rittinger, 2005). The phagocytic enzyme is normally quiescent, but becomes activated during the neutrophil oxidative burst when it generates large amounts of superoxide (Brandes \& Kreuzer, 2005). The classical phagocytic NADPH oxidase is composed of two subunits, a catalytic subunit gp91phox (91 kDa glycosylated protein; where phox is phagocyte oxidase), and p22phox subunit forming a membrane-bound heterodimeric flavo-cytochrome $b_{558}$. For fully enzyme activation a number of cytosolic regulatory subunits are required namely p67phox, p47phox, p40phox and the small GTPase Rac2 which are translocated to and assembled with the membrane cytochrome in a highly regulated process (DeLeo \& Quinn, 1996) that involves the post-translational modification of several cytosolic subunits and specific protein-protein binding through tandem SH3 (Src homology) domains. The tight regulation of enzymatic activity is achieved by two mechanisms: the separation of the oxidase subunits into different subcellular locations during the resting state and the modulation of reversible protein-protein and protein-lipid interactions. In the activated enzyme complex, the flavin-containing catalytic subunit functions as an electron transport system which uses NADPH as a donor of electrons that are transferred to molecular oxygen, resulting in the generation of superoxide.

Initially, several homologues of the gp91phox catalytic subunit have been identified, each encoded by separate genes and designated Noxs. These are now seven members: Nox1, Nox2, Nox3, Nox4, Nox5, Duox1 and Duox2. Nox2 contains gp91phox. It seems that all the Nox homologues may bind to p22phox in a similar manner to the gp91phox / p22phox complex. In the case of Nox1, homologues of p47phox and p67phox (NOXO1 and NOXA1) have been found to be important for its activation. On the other side, Nox4 activation does not require either p47phox and p67phox (Ray \& Shah, 2005).

ECs express all the classical NADPH oxidase subunits. However, there are a few significant differences between phagocytic oxidase and the enzyme in ECs. Firstly, endothelial oxidase 
continuously generates small amounts of superoxide even in unstimulated cells, but its activity can be augmented by specific agonists. Secondly, a large proportion of the superoxide generated in ECs is intracellular, whereas neutrophil superoxide generation is mainly in the extracellular compartment. The Nox2 oxidase is predominantly located in a perinuclear distribution in association with the cytoskeleton. There are also many fully preassembled ROS generating oxidase complexes which can explain both the continuous low-level superoxide generation in unstimulated endothelium and the intracellular site of ROS production. The Nox4 isoform is expressed in greater amounts in ECs and seems to contribute to the basal constitutive superoxide generation.. Additionally, ECs express the Nox1 enzyme in smaller amounts than the Nox2 isoform. Endothelial NADPH oxidase may be stimulated by a variety of (patho)physiological stimuli: 1. Agonists of G-protein coupled receptors such as angiotensin II and endothelin, 2. Growth factors such as thrombin and vascular endothelial growth factor, 3. Cytokines such as TNF- $\alpha, 4$. Metabolic factors such as increased glucose, insulin, non-esterified fatty acids, advanced glycation end products, 5 . Oxidized lipids, 6. Oscillatory shear stress, and 7. Hypoxia/reoxygenation and nutrient deprivation.

A major mechanism involved in NADPH oxidase activation is the PKC (protein kinase C)dependent phosphorylation of the p47phox regulatory subunit and its translocation to the membrane heterodimer. TNF- $\alpha$ induced endothelial oxidase activation downstream phosphorylation of extracellular signal-regulated kinase, involves not only the phosphorylation of p47phox, but also its binding to TRAF4 (TNF-receptor associated factor 4) (Li et al., 2005). The other mechanism, occurs via the action of Src, EGF receptor transactivation and the subsequend activation of PI3- kinase which leads to the robust activation of Rac and an enhanced and prolonged oxidase dependent ROS production. The activation of the oxidase by Rac 1 is therapeutically relevant because Rac 1 activation requires its post-translational modification by isoprenylation, a process that is inhibited by $\beta$-hydroxy-3-methylglutarylCoA reductase inhibitors (statins).

\section{Endothelial cell activation}

Generally, ECs are constantly a target for a wide variety of stimuli which can induce an EC response in three different ways: 1) stimulation - a rapid response of resting ECs initiated by agonists such as histamine, 2) activation - a slower protein synthesis-dependent response mostly initiated by inflammatory cytokines, (these two responses are normal EC functions), 3) injury - a process occurring by strong stimuli which can induce either endothelial necrosis or endothelial dysfunction.

A large number of distinct pathogens including viruses, bacteria and their products, protozoa, anti-EC antibodies, reactive oxygen species, rickettsiae and toxins can be directly or indirectly involved in EC activation (Figure 1). ECs can be also a target for angiogenic signals in neoplasia, and a major target for an immune reaction directed against alloantigens or xenoantigens. Some of them (like viruses) infect ECs, others (viruses, bacteria and their products, anti-EC antibodies) interact with ECs and induce or modify cytokine production.

EC activation triggered by inflammatory cytokines (e.g. TNF- $\alpha$, IFN- $\gamma$, IL-1) or growth factors (e.g. angiotensin II) can induce the expression of a functional program related to thrombosis and inflammation. Thus, under stronger insults ECs initially acquire a proinflammatory and procoagulant phenotype. Since the ultimate goal of the activated EC is to survive, it 
leads the cell to add to the constitutively- expressed protective machinery by initiating the upregulation of a new set of protective genes, including those for A1 and A20 (Bach et al., 1997).

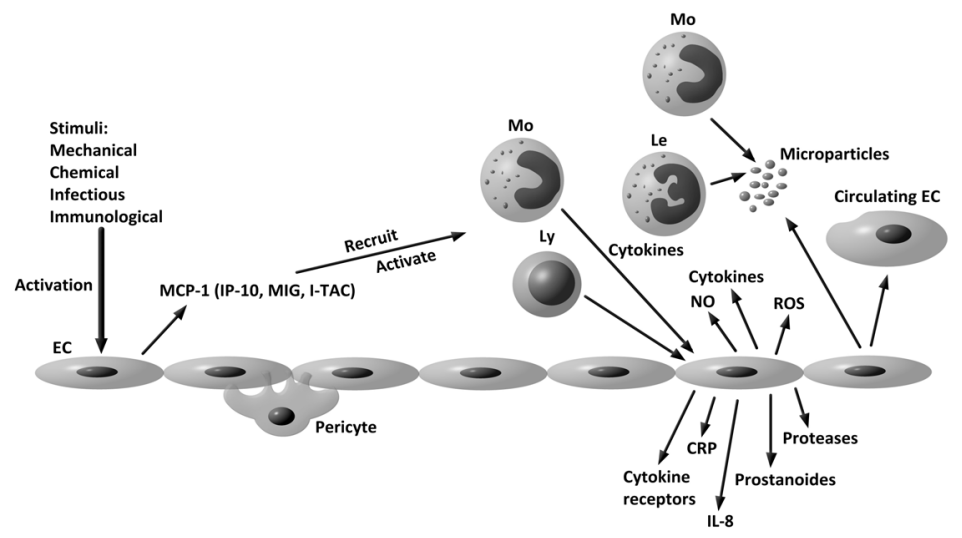

Fig. 1. Endothelial cell activation

During activation ECs not only develop a characteristic morphology but also synthesize a new surface protein and soluble mediators not present in the resting vascular endothelium. Many of these morphologic and functional changes can be induced in cultured ECs by purified immune mediators, such as monokines, lymphokines and bacterial LPS. Numerous inducible genes involved in endothelial activation, including cell adhesion molecule 1, Eselectin, tissue factor, interleukin-1 (IL-1), interleukin-6 (IL-6), G-CSF, interleukin-8 (IL-8) and c-myc contain elements in their promoter regions that could be recognized by the NF$\kappa \mathrm{B} 1 /$ Rel family of transcription factors. ECs also express an inhibitor of NF-кB, IкB- $\alpha$, and can dramaticaly modulate the level of this inhibitor in parallel with the activation process.

One of the earliest changes in the endothelium activation is an alteration in the glycocalyx composition. Glycocalyx contains anchoring proteoglycans (CD44, the syndecan protein family) and conecting glycosaminoglycans. The major class of negatively charged polysaccharides that contribute to the glycocalyx include heparan sulfate, chondroitin sulfate and the nonsulfated hyaluronan. The various combinations of possible sulfation modifications within a heparan sulfate chain can give rise to many structurally distinct binding sites for a wide rage of different ligands, including chemokines, growth factors, lipoproteins, lipases, serine protease inhibitors, thrombomodulin, extracellular SOD and complement factors (Weinbaum et al., 2007). The endothelial glycocalyx (Tarbell \& Ebong, 2008) markedly changes its properties under inflammatory conditions which facilitates rolling adhesion and tight adhesion of leucocytes. Cytokines activate proteases either located in glycocalyx or secreted by activated ECs and leucocytes which partially degrade the glycocalyx layer and thereby provide a mechanism for leucocyte recruitment (Mulivor \& Lipowsky, 2004). Also, the release of glycocalyx components into the circulation can be considered as a very early sign of endothelial activation. So, syndecan 1 and heparan sulfates have been shown to be released from the endothelium following stimulation by thrombin or endotoxin (Fitzgerald et al., 2000), and circulating glycocalyx components have been explored as a measure of endothelial activation in patients with type 2 diabetes and the coronary artery disease 
(Bruegger et al., 2009; Wang et al., 2009). During sustained endothelial activation platelets and leucocytes bind to the endothelial surface leading to the formation of proinflammatory factors such as thrombin and the membrane attached complex which can cause further activation of the endothelium and promote the formation of membrane particules so called microparticles. Microparticles from ECs, platelets and leucocytes are released into the circulation. The interaction between ECs and pericytes is disrapted and pericytes begins to produce proteases that damage the endothelial basement membrane. These processes may lead to the apoptosis or necrosis of ECs or ECs can be detached and detected in the circulation (Haubitz \& Woywodt, 2004).

\subsection{Nuclear factor-kB}

$\mathrm{NF}-\mathrm{KB}$ is a redox sensitive transcription factor associated with rapid-response activation mechanisms. It consists of homo- or heterodimeric complexes of members of the Rel family of proteins: p50/p105 (NF-kB1, derived from its p105 precursor), p52/100 (NF-kB2 and its p100 precursor), p65/RelA, c-Rel and Rel-B. The best characterized form is the heterodimer p50/p65. These proteins share a 300 amino acid region known as the Rel homology domain, which mediates DNA binding and dimerization. In resting cells, NF-kB binding proteins are in an inactive cytosolic form and are complexed to members of a family of inhibitory proteins referred to as ІкB (ІкB- $\alpha$, ІкB- $\beta$, ІкB- $\gamma$, ІкB- $\sigma$ and ІкB- $\varepsilon$ ). ІкB- $\alpha$ is the best characterized inhibitor, which binds to the p65 subunit of NF-kB (Baldwin, 1996). All IкB forms contain multiple ankyrin repeats which are involved in interactions with NF-kB. NF-kB can be activated by a number of divers agents such as the citokines, IL-1 $\beta$, and TNF- $\alpha$, LPS, oxidative stress, oxidatively modified LDL particles, viral products, advanced glycosylation end products and physical forces. These stimuli may activate the NF- $\mathrm{kB}$ kinase complex through distinct signaling pathways that culminate in the activation of the IкB kinase. In this way they induce IKB- $\alpha$ release from the p65 subunit after its phosphorilation. After phosphorilation IкB is ubiquitinated and targeted for degradation via the nonlysosomal ATP-dependent proteosome pathway followed by a rapid loss of this protein. Alterations in IкB- $\alpha$ at the levels Ser ${ }^{32}$ and Ser ${ }^{36}$, which prevent its phosphorilation and degradation, lead to blocking IкB- $\alpha$ ubiquitination and subsequent degradation (Brown et al., 1995). A removal of IкB- $\alpha$ exposes a nuclear localisation sequence in NF- $\mathrm{KB}$ which is then able to translocate to the nucleus, bind to a specific DNA sequence (5'-GGGRNNYYCC-3') and activate NF- $\mathrm{kB}$ dependent genes.

IKB- $\alpha$ is rapidly resinthesized after the loss, suggesting an autoregulatory mechanism for NF- $\mathrm{kB}$ regulation in the endothelium (Thurberg \& Collins, 1998). When the IкB- $\alpha$ pool is replenished, IкB- $\alpha$ translocates to the nucleus and displaces the transactivating form of NF$\kappa \mathrm{B}$ from promotor elements. The NF- $\mathrm{BB} / \mathrm{I \kappa B}-\alpha$ complex is then transported back to the cytoplasm in the inactive form. Further, the genes that code for p65, p105 and IкB- $\alpha$ are highly inducible in ECs in response to the stimuli that activate NF- $\mathrm{kB}$. The promoter of the IкB- $\alpha$-gene contains $\kappa B$ binding sites. p65 stimulates IкB- $\alpha$ gene expression (Baldwin, 1996) and p65 stabilises IкB- $\alpha$ protein indicating that p65 and ІкB- $\alpha$ have been directly linked in an autoregulatory loop. The NF-кB/IкB- $\alpha$ autoregulatory system may ensure that the induction of NF- $\mathrm{kB}$ is transient, and that the activated cell returns to a quiescent state. It allows a continuous maintenance of the cytoplasmatic reservoirs of NF- $\mathrm{kB}$ complexes for stimulation in an acute response, and also prepares the EC to return NF-kB to its uninduced condition. 
The rapid cytokine-induced activation of NF-KB in ECs is probably similar to that seen in other cell types. However, the recovery kinetics of the NF-kB/IкB- $\alpha$ response in the endothelium may be different. The NF- $\mathrm{kB}$ remains activated and IкB- $\alpha$ levels remain below basal levels for long periods of time than seen in cells programmed for rapid responses, such as macrophages (Read et al., 1994). It is possible that cytokines released by activated ECs result in an autocrine activation of NF- $\mathrm{kB}$ and continued degradation of IкB- $\alpha$. Such prolonged endothelial activation may play a role in recruiting circulating cells to the sites of ongoing inflammatory (artherosclerosis) (Ahn et al., 2006; Brand et al., 1997) or immune processes (autoimmune diseases). The NF-kB activation can be blocked by sodium salicylate and aspirin (Kopp \& Ghosh, 1994).

However, in addition to the proinflammatory genes, activated NF-kB may induce a set of protective genes, including antiapoptotic genes that may limit the activation process and thereby regulate the respons to injury. The protective genes include IкB- $\alpha$ and hemoxygenase, as well as the antiapoptotic genes A20, Bcl-2, and Bcl-XL. Besides the antiapoptotic activity, the antiapoptotic genes also inhibit the activation of NF-kB in ECs and thus block the induction of the proinflammatory genes (Bach et al., 1997). Some stimuli, such as laminar shear stress, upregulate genes for manganese superoxide dismutase, cyclooxygenase- 2 and endothelial specific nitric oxide synthase. Since this set of genes has antioxidant, antithrombotic and antiadhesive properties, they can be also recognised as "protective". When the protective effect is not adequate, ECs undergo apoptosis.

To maintain an antiinflammatory and anticoagulant state the endothelium also requires environmental cues. Laminar shear stress is a key contributor to the integrity of ECs through the inhibition of apoptosis. Shear stress also activates specific transcription factors, such as kruppel-like factor 2 and nuclear factor erythroid 2-related factor 2 (Dekker et al., 2002; Chen et al., 2003). These transcription factors regulate about $70 \%$ of the genes responsive to shear stress, including those that encode typical protective endothelial factors such as eNOS, thrombomodulin and antioxidant enzymes, but at the same time they down regulate genes that encode procoagulant factors such as plasminogen activator inhibitor 1, IL-8 and the tissue factor (Fledderus et al., 2008). It seems that kruppel-like factor 2 can be directly regulated by shear stress, while the nuclear factor erythroid 2-related factor 2 is released from its inhibitor, kelch-like ECH associated protein 1, through the generation of ROS, which suggests that it functions as a defense mechanism against antioxidants (Kraft et al., 2004).

However, in the stabilisation of the endothelial phenotype a key role belongs to the reciprocal interaction of stromal or epithelial cells with the endothelium. ECs have direct physical contact with pericytes and vascular smooth muscle cells through myoendothelial junctions. Pericytes send signals to the endothelium through number of factors including hydrogen sulfide, all isoforms of VEGF (vascular endothelial growth factor), sphingosine-1-phosphate, platelet-derived growth factor, basic fibroblast growth factor and angiopoietin I (Gaengel et al., 2009; Diaz-Flores et al., 2009). Angiopoietin I is best known to stabilize the endothelium and to maintain its quiescent state. If the signaling between angiopoietin I and the ECs is interrupted ECs sprout and migrate; this results in neoangiogenesis (Chen \& Stinnett, 2008).

\subsubsection{Regulation of NF-kB dependent gene expression}

The activation of the pleiotropic mediator NF-KB in ECs could coordinate the expression of numerous endothelial products which are important in endothelial activation including some cell surface adhesion proteins, cytokines, growth factors, NADPH oxidase, NOS, prostanoides, acute phase reactants and components of the coagulation system. They may 
be multiple phosphorylation events which play a key role in NF-kB activation. Some of the cytosolic NF- $\mathrm{KB} / \mathrm{I \kappa B}-\alpha$ is associated with the catalitic subunit of the cAMP-dependent protein kinase, PKAc, in an inactive state. The signal-induced degradation of IKB- $\alpha$ leads to the activation of PKAc which phosphorilates the p65 subunit of NF- $\mathrm{kB}$ on Ser ${ }^{276}$. This causes a conformational change which unmasks the CREB binding protein (cAMP-responsive binding protein) interacting domain on p65. Once CREB interacting domain on p65 is unmasked, NF-KB interaction with a coactivator is enhanced and NF- $\mathrm{KB}$ can enter the nucleus (Zhong et al., 1997). Lysophosphatidylcholine, one of the active molecules present in oxLDL, has been shown to activate NF- $\mathrm{kB}$ in primary cultured ECs via a PKC dependent pathway. ECs can also be shown to be responsive to oxLDL in vivo. When unmodified human LDL particles are injected into a rat model, they are localized in the arterial wall were they undergo oxidative modification which is accompanied by an increase in endothelial NF- $\mathrm{kB}$ activation and expression of NF- $\mathrm{kB}$ dependent genes (Calara et al., 1998). In the nucleus, the p65 subunit can be phosphoregulated by the components of the p38 and ERK MAP kinase signal patways (Berghe et al., 1998).

\section{Endothelial cells and inflammation}

ECs actively participate in the inflammatory process acting as both a target and a responder to a variety of stimuli. Whatever the initial stimuli (mechanical, chemical, infectious or immunological) they activate ECs. There are two stages of EC activation; the first-EC activation type I which does not require de novo protein synthesis or gene upregulation, occurs rapidly and it is followed by the retraction of ECs, expression of $\mathrm{P}$ selectin and release of von Willebrand factor. The second response, EC activation type II, requires time for the stimulating agent to cause an effect via gene transcription and protein synthesis. A stimulating agent acting on the EC surface causes the expression of many genes via the activation of NF-KB (Baldwin, 1996). EC activation is a graded rather than an all response. For example, changes in EC integrity range from simple increases in local permeability to major EC contraction, exposing large areas of subendothelium. Activation may proceed as an acute response or as a chronic EC activation such as in atherosclerosis and in vascular diabetic complications. Ligands of RAGE (the receptor for advanced glycation end products) mediate continuous NF- $\mathrm{KB}$ activation which results in persistent endothelial tissue factor induction. The activation may occur locally, as in transplant rejection, or systematically, as in septicaemia and the systemic inflammatory response.

Generaly, EC activation is associated with five core changes including the loss of vascular integrity, expression of leucocyte adhesion molecules, change in phenotype from antithrombotic to prothrombotic, cytokine production and upregulation of HLA molecules. The loss of vascular integrity can expose subendothelium and cause the efflux of fluids from the intravascular space.

The first step in EC activation, independently on the initial stimuli, involves inflammatory cytokines mostly TNF- $\alpha$, IL-1 and IFN- $\gamma$ (Steiner et al., 1997). They stimulate ECs to produce monocyte chemotactic protein-1 (MCP-1). Vascular cells produce three more chemokines including IP-10, MIG, I-TAC, when exposed to the inflammatory mediator IFN- $\gamma$, a molecule produced by activated $\mathrm{T}$ cells and perheps macrophages. MCP-1 recruits and activates immune and inflammatory cells which produce inflammatory cytokines and induce the expression of adhesion molecules. The upregulation of surface glycoproteins such as 
endothelial leucocyte adhesion molecule-1 (ELAM-1, also known as E-selectin), intercellular adhesion molecule-1 (ICAM-1), vascular cell adhesion molecule-1 (VCAM-1) and MHC molecules allows leucocytes to adhere to the endothelium and then move into tissues.

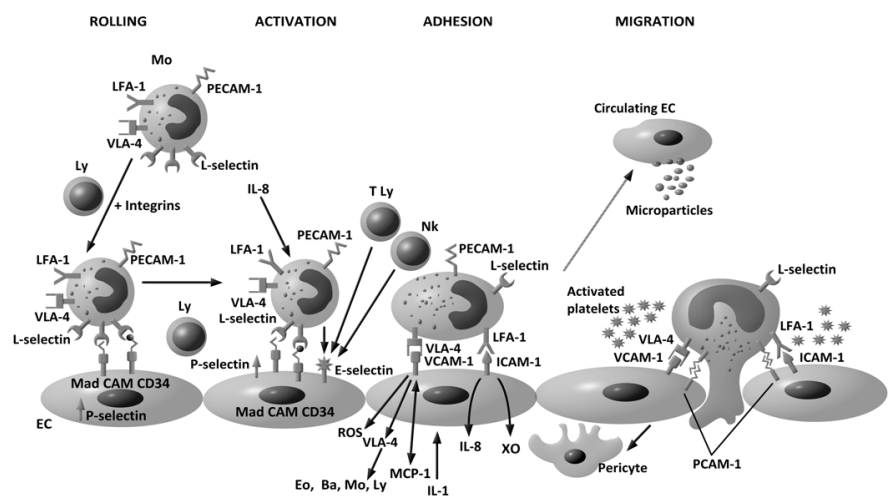

Fig. 2. Endothelial cells and inflammation

Tissue infiltration by circulating leucocytes is a four-step process involving low affinity attachment, roling on the endothelium, high affinity attachment to the endothelium, followed by transmigration across the ECs lining blood vessel walls. These processes are mediated by adhesion molecules. Four distinct families of adhesion molecules including cadherins, immunoglobulin superfamily members, selectins and integrins are involved in vascular cell-cell adhesion. These molecules are requred four: 1 . The formation of the junctional complexes that enable the assembly of ECs into functional vascular networks; 2 . They mediate the leucocyte-endothelial adhesive interactions involved in the trafficking of leucocytes out of the circulation but the set of adhesion molecules expressed by ECs depends on the stimuli (Cook-Mills \& Deem, 2005) while the specificity of the adhesion molecules regulates the specificity of leucocyte homing to tissues; and 3. They contribute to contacts between pericytes and the endothelium that are important to the regulation of EC proliferation, addressin interaction, rolling which can also be mediated by the interaction of leucocyte $\alpha 4 \beta 1$-integrin and VCAM-1/CD106. A transitory contact of leucocytes with the endothelium or their rolling are mediated by low-affinity receptors, selectins and addressins.

The binding of selectins on leucocytes stimulates "outside-in" signals in leucocytes, increasing the affinity of the integrin family of receptors, which then bind to EC adhesion molecules such as ICAM-1/CD54 and VCAM-1. The regulation of the expression of the adhesion molecules occurs by negative control as well as at the level of gene transcription. For example, $\mathrm{NO}$ can reduce leucocyte adhesion to arteries and can counteract the induction of VCAM-1 expression by ECs stimulated by inflammatory cytokines such as IL-1 or TNF- $\alpha$. At the transcriptional level, NO inhibits VCAM-1 gene expression in ECs by interfering with the NF-kB signaling pathway via a non-cyclic GMP-mediated mechanism (Peng et al., 1995). Instead, NO inhibits NF-kB by inducing its inhibitor IкB- $\alpha$. Thus, NO acts as an anti-inflammatory mediator. Leucocyte integrin affinity is also rapidly increased by "inside-out" signals from leucocyte chemokine receptors triggered by chemokines expressed on the surface of ECs. When leucocyte integrin affinity is increased, leucocyte roling is arrested. 
More sustained sticking of leucocyte to the endothelium is mediated by VCAM-1 which binds to the cognate ligand VLA-4 (very late adhesion molecule-4) that is expressed by the very types of leucocytes recruited to the intima: monocytes and lymphocytes, respectively. Once adherent, the leucocytes enter the vascular wall. Leucocyte migration from the blood into tissues is vital for immune surveillance and inflammation. Leucocytes can stimulate "outside-in" signal transduction in ECs and some of these signals can cause localized alterations in EC junctions.

At the sites of inflammation, activated antigen specific lymphocytes are the first to migrate across activated endothelium expressing adhesiom molecules. During the leucocyte-EC interaction, the EC promotes the migration of leucocytes or removes leucocytes that are in the early stages of apoptosis. Leucocytes can be found within the vacuolar structures of ECs only when ECs phagocytose apoptotic leucocytes. This function of ECs may be a mechanism by which the endothelium is protected from the localised vascular damage which would occur if apoptotic leucocytes were to undergo necrosis. Thus, we can say that ECs modulate leucocyte migration by promoting leucocyte migration or removing leucocytes undergoing apoptosis.

While lymphocytes migrate acros activated endothelium neutrophils and monocytes migrate between ECs (Mamdouh et al., 2003). It has been shown that neutrophils roll across the luminal surface of human umbilical vein ECs to bicellular and tricellular EC junctions. In response to peptid $\mathrm{N}$-formyl-methionyl-leucyl-phenylalanine neutrophils migrate through a pore in nonactivated cutaneous ECs. Adhesion molecule signals result in alterations in the function of cell junction proteins and/or contractile forces in the EC, thereby opening an EC junction and permitting leucocyte migration into the tissue. During neutrophil and monocyte migration, localized EC retraction of lateral junctions occurs at the site of leucocyte migration showing that contractile forces in ECs have an active role in leucocyte migration.

\subsection{Selectins}

Three selectins have been characterized and named according to their cell of original discovery: P-selectin (platelet selectin), E-selectin (EC selectin) and L-selectin (leucocyte selectin). These are glycosylated proteins, which share several structural features and support leukocyte-EC and leukocyte-platelet adhesion. L-selectin is constitutively expressed by most leucocytes, but not by other cell-types. The ECs of high endothelial venules of lymph nodes constitutively express ligand for L-selectin (lymphocyte homing receptors) and L-selectin plays a central role in the normal recirculation of lymphocytes. ECs from other vascular beds also support L-selectin-mediated adhesion after the exposure to cytokines. P-selectin, which is expressed by ECs and platelets, is stored in intracellular granules and mobilized to the surface upon cell activation where it supports the adhesion of granulocytes, monocytes and some lymphocyte subsets. E-selectin is expressed by cytokine-activated ECs and supports adhesion of granulocytes, monocytes, some memory T-lymphocytes and natural killer cells (Bevilacqua \& Nelson, 1993; Brady, 1994).

\subsection{Integrins}

Selectin - mediated adhesion facilitates the immobilization of phagocytes by the interaction of phagocyte integrins with immunoglobulin-like molecules on the endothelium. Integrins are heterodimeric glycoproteins composed of non-covalently associated $\alpha$ and $\beta$ subunits. Integrins mediate diverse cell-cell and cell-matrix interactions. The most important integrins 
in leukocyte-endothelial adhesion include the very late activation antigen-4 $\beta 1$ integrin (VLA-4) and the CD11/CD18 $\beta-2$ integrins. VLA-4 is constitutively expressed by lymphocytes, monocytes, basophiles and eosinophils, but not neutrophils. This protein is a ligand for the inducible vascular cell adhesion molecule-1 (VCAM-1) and also mediates cell attachment to fibronectin and possibly other matrix components. $\beta-2$ integrins include three well characterized members: CD11a/CD18 (LFA-1, Lymphocyte function-associated antigen-1), CD11b/CD18 (Mac-1) and CD11c/CD18 where CD11 and CD18 are the $\alpha$ and $\beta$ subunits, respectively. LFA-1 is found on all T-cells and also on B-cells, macrophages and neutrophils. CD11 subunits are encoded by distinct genes in a cluster on chromosome 16, while CD18 is encoded by a single gene on chromosome 21. CD18 contains a short cytoplasmic tail which has several potential phosphoregulation sites, a highly conserved transmembrane domain and a long extracellular region which contains a conserved cysteinrich region that is necessary for surface expression (Brady, 1994). The major ligands for CD11a/CD18 are the intercellular adhesion molecules- 1 and 2 (ICAM-1 and ICAM-2). ICAM-1 is also a ligand for CD11b/CD18 which supports phagocyte adhesion to cellular and acellular substrates by ICAM-1 independent mechanisms. Other ligands for CD11b/CD18 include fibrinogen, clotting factors and complement fragments (C3bi).

\subsection{Immunoglobulin-like molecules}

\subsubsection{Platelet-EC adhesion molecule-1 (PECAM-1)}

PECAM-1 adhesion at the lateral borders of nonactivated ECs participates in the formation of EC junctions and my be a critical regulator of phagocyte diapedesis between ECs. PECAM-1 also mediates the binding with PECAM-1 on leucocytes. Although there is PECAM-1 independent models of lymphocyte, neutrophil and monocyte migration antiPECAM-1 antibodies can block monocyte diapedesis across TNF-a or IL-1 $\beta$-activated ECs (Schenkel et al., 2002). PECAM-1 can activate signals that increase leukocyte adhesion (Chiba et al., 1999). Also, PECAM-1 has been shown to recycle between the cell membrane and a cytoplasmic compartment juxtaposed to the membrane. PECAM-1 is recruited to the EC surface at the sites of monocyte transmigration (Mamdouh et al., 2003). A treatment of nonactivated cells with an inducer of oxidative stress increases PECAM-1 phosphorylation followed by an increase in leukocyte migration. PECAM-1 phosphorylation is regulated by ser/thr phosphatases which can be blocked with anti-PECAM-1 antibodies, antioxidants or inhibitors of PKC, Ras and glutathione synthesis (Rattan et al., 1997). The homophilic adhesion of PECAM-1 stimulates its binding to several intracellular proteins involved in signaling including Src homology containing phosphatase, phospholipase C- $\gamma$ and Pi-3k (Jackson et al., 1997; Pellegatta et al., 1998; Pumphrey et al., 1999). Phosphorylated PECAM-1 can be linked to the cytoskeletal catenins thereby limiting their translocation to the nucleus thus modulating gene expression.

PECAM-1 localization in ECs is modulated by cytokines. The simultaneous treatment with TNF- $\alpha$ and IFN- $\gamma$ moves PECAM-1 out of lateral junctions without inhibiting the ability of monocytes to migrate across these ECs under laminar flow conditions suggesting that sufficient PECAM-1 is still available for migration (Shaw et al., 2001).

\subsubsection{Intercellular adhesion molecule-1 (ICAM-1)}

ICAM-1 is a glycoprotein which contains five tandem immunoglobulin domains. It is constituvely expressed on many cell types but can be increased on endothelium by 
inflammatory mediators (Roebuck \& Finnegan, 1999). The first and third immunoglobulinlike domain of ICAM-1 bind to the counter-receptors of LFA-1 and membrane-activated complex-1 (CD11b/CD18) respectively, on leucocytes, but it can also bind to fibrinogen on lymphocytes (Dupperay et al., 1997). A chelation of intracellular calcium or the inhibition of PKC in IFN- $\gamma$ treated brain EC lines blocks ICAM-1 dependent lymphocyte migration without affecting lymphocyte adhesion (Etienne-Manneville et al., 2000). ICAM-1 stimulates ECs to produce chemokines through the activation of ERK1 and ERK2 (Sano et al., 1998) suggesting that ICAM-1 induces EC signals that are required for lymphocyte migration.

ICAM-1 signals can also regulate the EC actin cytoskeletion. The antibody cross-linking of ICAM-1 on TNF-a-activated pulmonary microvascular ECs activates xanthine oxidase and p38 MAPK (Wang \& Doerschuk, 2001), resulting in actin rearrangement, and can also induce phosphorylation of another cytoskeleton protein ezrin. ICAM-1 associates with the cytoskeletal protein ezrin through phosphatidylinositol 4,5-biphosphate (Heiska et al., 1998).

Homotypic and heterotypic lymphocyte adhesion mediated by the interaction of ICAM-1 and CD11a/CD18 facilitates other important lymphocyte functions including antigen recognition, lymphocyte co-stimulation and cytotoxicity.

\subsubsection{Vascular cell adhesion molecule-1 (VCAM-1)}

VCAM-1 is a glycoprotein containing seven immunoglobulin-like domains which predominates in ECs. A second form of VCAM-1, consisting of six immunoglobulin-like domains, is produced in some tissues by alternate splicing. VCAM-1 is constitutively expressed at low levels by ECs and can be induced on these and other cell-types by cytokines. VCAM-1 supports the adhesion of eosinophils, basophils, monocytes and lymphocytes but not neutrophils, through the interaction with VLA-4. The binding of lymphocytes to VCAM-1 stimulates localized EC-shape changes and the "opening of a narrow passage way" through which leucocytes can migrate (Cook-Mills \& Deem, 2005; Matheny et al., 2000). Lymphocyte binding to VCAM-1 activates ECs NADPH oxidase for the generation of ROS in ECs which constitutively express VCAM-1 and the MCP-1. The VCAM-1-mediated activation of $\mathrm{NADPH}$ oxidase is dependent on calcium flux and the small molecular weight $\mathrm{G}$ protein Rac1. Rac1 is involved in the assembly of the active NAPH oxidase complex in ECs such as in neutrophils (Dorseuil et al., 1995).

ICAM-1 and PECAM-1 do not activate EC NADPH oxidase. The VCAM-1-stimulated EC NADPH oxidase activity is required for VCAM-1-dependent lymphocyte migration because the inhibition of EC NADPH oxidase blocks MCP-1 stimulated, VCAM-1 dependent lymphocyte migration without altering lymphocyte adhesion. ROS scavengers inhibit VCAM-1 dependent lymphocyte migration while VCAM-1 dependent lymphocyte migration is not blocked by the inhibition of ROS-generating enzymes NOS, xanthine oxidase or cytochrome p450 on ECs (Matheny et al., 2000).

Lymphocyte binding to VCAM-1 induces a low concentration of hydrogen peroxide $(1 \mu \mathrm{mol})$ production in ECs (Tudor et al., 2001) much lower than those $(50-200 \mu \mathrm{mol})$ produced by neutrophils and macrophages for the destruction of pathogens (DeLeo \& Quinn, 1996) or released in some diseases (Thannickal \& Fanburg, 2000). Low levels of ROS induce rapid, transient and reversible signals. This is important, since once a leucocytes reach an EC junction, the process of transmigration occurs within a couple of minutes. Another function of the ROS produced during VCAM-1-dependent lymphocyte migration is the activation (within minutes) of matrix metalloproteinases (MMPs) associated with ECs or IL-4 activated 
ones. The EC-derived hydrogen peroxide also activates lymphocyte-associated MMPs but 25 hours later. These results show that the ECs-associated rather than the lymphocyteassociated MMPs are required for VCAM-1-dependent lymphocyte migration across VCAM-1-expressing ECs (Deem \& Cook-Mills, 2004).

Hydrogen peroxide produced by VCAM-1 stimulation has a direct, rapid effect on ECassociated MMPs. ROS activate purified MMPs by oxidizing the cysteine in the propeptide arm opening the arm and exposing the MMP active site (Murphy et al., 1994) which stimulate the autocatalytic removal of the arm, forming an active MMP (Van Wart \& BirkedalHansen, 1990). Contrary to EC-associated MMPs, hydrogen peroxide indirectly activates lymphocyte-associated MMPs through the down-regulation of the expression of the high levels of tissue inhibitors of MMPs (TIMPs) on lymphocytes (Deem \& Cook-Mills, 2004) which takes several hours indicating that lymphocyte MMPs are likely involved in the leukocyte migration through the extravascular tissue (Cook-Mills \& Deem, 2005).

MMPs associated with ECs are more important than secreted MMPs during lymphocyte migration. Among MMPs the EC-associated MMP-2 and MMP-9 are likely to degrade matrix and EC junction molecules at the site of transmigration (Herren et al., 1998).

\section{Endothelial cells and vasculitis}

\subsection{Vasculitis triggered by infectious agents}

Vasculitis can be a primary disease, that is not associated with another cause. Or, it may be a complication of some other diseases such as infections, malignancy, reactions to certain medications (Zhang et al., 2010), a complication after an organ transplant, a connective tissue disease or other causes.

The participation of ECs in the pathogenesis of vascular inflammation is complex. On one hand, the vascular endothelium may be the target for injury. On the other hand, ECs may actively participate in amplifying and maintaining the inflammatory process. The role of ECs seems to be more prominent in small vessel vasculitis, such as hypersensitivity vasculitis and vasculitis associated with antineutrophil cytoplasmic antibodies (ANCA). In larger vessel vasculitis, ECs are the crucial protagonist of the vascular response to inflammation which leads to the amplification of the inflammatory response, vessel remodeling and repair, and eventually, vessel occlusion, which is the source of some of the most severe complications in patients with systemic vasculitis.

Although most of the infection related vasculitides are immune-complex-mediated (hepatitis B virus-related polyarteritis nodosa, and hepatitis C virus associated cryoglobulinemia) some pathogens are able to directly infect the ECs. Primary vasculitis can be induced by several pathogenic mechanisms. The direct infection of ECs include: bacterial vasculitis (naisserial), spirochetal vasculitis (syphilitic), mycobacterial vasculitis (tuberculous), rickettsial vasculitis (Rocky Mountain spotted fever), fungal vasculitis (aspergillosis) and viral vasculitis (herpes virus, herpes zoster) (Heeringa et al., 2004). Rickettsiae and herpes virus family members, particularly cytomegalovirus are the best documented (Mandell \& Calabrese, 1998). Serious infections by these agents frequently include vasculitis lesions. The proliferation of the rickettsial organism in small-vessel walls elicits an inflammatory response that results in focal vascular inflammation, often with necrosis and hemorrhage. However most forms of vasculitis do not appear to be caused by the direct infection of vessel walls by pathogens. 


\subsection{Immune complex-mediated vasculitis}

Noninfection immunologic mechanisms that cause vasculitis include cell-mediated inflammation, immune complex-mediated inflammation and inflammation induced by ANCA. Immune complex-mediated vasculitis include: cryoglobulinemic vasculitis, HenochSchonlein purpura, serum sickness vasculitis, lupus vasculitis, infection-induced immune complex vasculitis (hepatitis virus), some drug-induced vasculitis (sulfonamide-induced vasculitis), some paraneoplastic vasculitis, and Goodpasture's syndrome (mediated by anti GMB antibodies) (Heeringa at al., 2004).

In immune complex-mediated vasculitis, EC morphology is altered and the luminal endothelium may be destroyed. Complement-mediated lysis as well as neutrophil-mediated EC damage are the main mechanisms of endothelium cell injury in these processes (Cid, 2002). The membrane attack complex C5b-9, final product of the complement activation cascade, has been detected in the necrotizing vasculitis of the polyarteritis nodose type (Kissel et al., 1989).

\subsection{ANCA-mediated vasculitis}

Wegener's granulomatosis, microscopic polyangitis, and Churg-Strauss syndrome are the major forms of small-vessel vasculitis that are strongly associated with ANCA (Heeringa et al., 2004). ANCA vasculitis may be induced by some drugs, such as thiouracil. There are two clinically important forms: cytoplasmatic ANCA (cANCA) and perinuclear ANCA (pANCA). ANCA are autoantibodies that are directed against constituents of the primary granules of neutrophils and the peroxidase positive lysosomes of monocytes. The primary antigenic targets for ANCA are proteinase-3 (PR3), a $29 \mathrm{kD}$ neutral serin protease, and myeloperoxidase (MPO), a 140kD enzyme involved in the generation of ROS (Falk \& Jennette, 1988; Jennette et al., 1990). ANCA recognizes MPO or PR3 translocated to the neutrophil membrane on TNF-a or interleukin-8 (IL-8) primed neutrophils (Flint et al., 2010) or may bind to Fc receptors through their Fc portion. Both interactions, specific and Fcmediated appear to be functionally relevant (Falk et al., 1990; Porges et al., 1994). ANCA immunoglobulin $\mathrm{G}$ can activate neutrophils and monocytes. ANCA binding to neutrophils may stimulate or amplify many neutrophil functions including respiratory bursts which generate ROS, degranulation and protease release (Falk et al., 1990), NO production (Tse et al., 2001), and chemotactic activity. ANCA binding also stimulates integrin expression and integrin-mediated homotypic adhesion and adhesion to ECs (Radford et al., 2000). Homotypic interactions mediated by neutrophil integrins are required for enhanced TNF- $\mathrm{a}$ induced neutrophil activation by ANCA. ANCA-stimulated neutrophil function results in an augmentation of neutrophil-mediated EC injury by inducing EC detachment and lyse of ECs previously damaged by other mediators. Further, in an inflammatory microenvironment, enzymes released by activated neutrophils, including MPO and PR3, may induce EC apoptosis (Yang et al., 2001).

ANCA-mediated monocyte and neutrophil activation has also been shown to induce the expression and secretion of proinflammatory cytokines (IL-1, IL-6, IL-8, TNF- a), chemokines (MCP-1) and prostanoids (Cid, 2002; Cid et al., 2004). Such mediators may contribute to the amplification and propagation of the inflammatory process.

The detection of ANCA is an important diagnostic and prognostic marker. Testing of ANCA is indicated in patients with evidence for the ANCA disease such as severe pulmonary hemorrhage, especially if accompanied by evidence for glomerulonephritis, peripheral 
neuropathy, purpura, hemorrhagic sinusitis or other manifestations of small-vessel vasculitis.

However, the use of ANCA as a marker of the disease and its activity show a number of limitations such as the occurrence of high ANCA titers with no disease activity, or ANCA presence in non-vasculitis disorders, such as endocarditis (Choi et al., 2000) or tuberculosis (Flores-Suarez et al., 2003). In addition, circulating ECs have been used as markers in a variety of vascular disorders (Dignat-George \& Sampol, 2000) and also their use is demonstrated in ANCA-associated small-vessel vasculitis (Haubitz and Woywodt, 2004). Recently it has been documented that an increase risk for relapse appears to be related to the presence of anti-PR3 antibody seropositivity.

\subsection{Anti endothelial cell antibodies}

Circulating anti-EC antibodies have been detected in several vasculitides including Wegener's granulomatosis, microscopic polyangitis, Kawasaki diseases, thromboangiitis obliterans, Bechet's disease and Takayasu's arthritis (Praprotnik et al., 2001). It seems that a large, highly heterogeneous group of antigens can be recognized by anti-EC antibodies. Some anti-endothelial antibodies, such as those detected in Kawasaki disease, recognize cytokine-inducible molecules, while others, such as those detected in Wagener's granulomatosis and microscopic polyangitis, recognize constitutive EC antigens (Del Papa et al., 1996).

Studies in vitro have shown that some anti-EC antibodies may trigger complement activation or anti-body-dependent cellular cytotoxicity. These mechanisms might contribute to EC damage in systemic vasculitis. That alloantigens can activate ECs is well recognized within transplantation where HLA-specific antibodies can activate EC NF-kB (Savage \& Williams, 2007; Smith et al., 2000). EC antibodies arise most probably as a secondary event to endothelial injury. Initial endothelial injury may result from pathogenic processes that may be unleashed during the development of the vasculitis process itself (for example, by proteolytic enzymes released from neutrophils after their inappropriate activation by ANCA). It is also likely that sequestered viral infections, such as cytomegalo-virus that can replicate within ECs, may become relatively more activated during the development of an autoimmune response and particularly after the introduction of immnosuppression. That cytomegalovirus can induce anti-EC antibodies is recognized (Toyoda et al., 1999). The binding of anti-EC antibodies to EC in vitro elicits a calcium-flux, the secretion of the chemokines MCP-1 and GCP-2 (but not IL-8 or GRO- $\alpha$ ), and the upregulation of the ligands MHCclass I related antigen A (MICA) and vascular adhesion protein-1 (VAP-1). Signal transduction via the SAPK/JNK pathway appears to be important in the increased expression of MCP-1, GCP-2 and MICA. In addition, anti-EC antibodies also activate NF-kB. However, it has been demonstrated that anti-EC antibodies have an ability to induce EC apoptosis via the recognition of Hsp60 (Jamin et al., 2005). Once present, anti EC antibodies have the potential to inhibit potent antiinflammatory mechanisms (Nara et al., 2006).

\subsection{The endothelial cell as an inflammation amplifier}

ECs are able to amplify the inflammatory response by three main mechanisms: adhesion molecule expression, cytokine production and angiogenesis. Most of the primary immunopathogenic mechanisms playing a role in the pathogenesis of blood vessel inflammation in vasculitis include adhesion molecule expression and function (Cid et al., 2002). The studies 
in vitro show that complement activation products induce adhesion molecule expression by cultured ECs. C1q induces E-selectin, ICAM-1 and VCAM-1 (Del Papa et al., 1996) and C5a can upregulate P-selectin expression (Foreman et al., 1994). Immune complex and complement-mediated vessel damage in vivo require adhesion molecule expression and function. Also, ANCA binding to EC membrane-associated PR3 or related epitopes may induce Eselectin and VCAM-1 expression by ECs. PR3 released by neutrophils in the vicinity of ECs may induce EC ICAM-1 expression. Anti-EC antibody binding to ECs also induces endothelial adhesion molecule expression (Cid, 2002). The main inducers of endothelial adhesion molecules are the cytokines IL-1, TNF- $\alpha$ and IFN- $\gamma$ which are produced by activated lymphocytes and macrophages in an vasculitis area (Raines \& Ferri, 2005).

The expression of inducible adhesion molecules E-selectin and VCAM-1 by ECs as well as the upregulated constitutive expression of ICAM-1 were detected in patients with cutaneous leucocytoclastic vasculitis, Kawasaki disease, classical polyarteritis nodosa and gian-cell arteritis (Cid et al., 2000). In Wegener's granulomatosis, microscopic polyangitis and ANCA associated glomerulonephritis VCAM-1 and ICAM-1 expression were observed at the glomerular tuft as well as in tubular epithelial cells and peritubular capillaries (Rastaldi et al., 1996).

In small vessel vasculitis, endothelial adhesion molecule expression occurs in luminal endothelium (Sais et al., 1997). In medium-sized vasculitis, the luminal endothelium only expresses constitutive or inducible adhesion molecules at early stages. As the inflammatory process proceeds, the luminal endothelium is damaged and the vascular lumen is occluded. Then, endothelial adhesion molecules are expressed by adventitial neovessels (Coll-Vinent et al., 1998). In sclerotic glomeruli of kidney ANCA-associated vasculitis glomerular expression of ICAM-1 and VCAM-1 declines (Patey et al., 1996). In large-vessel vasculitis, adhesion molecule expression occurs in neovessels at the adventitia and at the intima/media junction. These observations suggest that infiltrating leucocytes penetrate the vessel wall through the adventitial vasa vasorum and neovessels in large- and medium-sized vessels.

In an inflammatory setting ECs have the potential to produce a variety of cytokines, chemokines and growth factors. In vasculitides a stimulation of ECs arises by ANCA binding, some anti-EC antibodies and cytokines released by infiltrating cells. By IL-1 $\alpha$ and IL-6 production ECs contribute to the systemic acute phase in many systemic vasculitides. Colony-stimulating factors produced by ECs prolong the half-life of infiltrating leucocytes, while chemokines (IL-8, RANTES, Gro $\alpha$ and SLC) selectively attract leucocyte subpopulations which bear specific receptors contributing to tissue targeting and amplifying vessel inflammation.

\section{Conclusion}

The endothelium has long been considered a passive physical barrier that only separates blood from tissues. Currently, it is clear that the endothelium is one of the most active organs which regulates many physiological functions and helps to coordinate functions of differentiated tissues in a way that meets the requirements of the organism as a whole. It has also emerged that ECs are the key immuno-reactive cells involved in host defence and inflammation. These cells both produce and react to a wide variety of mediators including cytokines, growth factors, adhesion molecules, vasoactive substances and chemokines, with effects on various cells. Prolonged or exaggerated endothelial activation leads to dysfunction (an early predclinical event of vascular disease) that is regulated by stromal cells and that 
can drive the vasculitis process with leucocyte recruitment, thrombosis and platelet plugging. Such local vascular inflammation has distant effects on the vascular endothelium leading to systemic endothelial dysfunction. Besides a whole panel of inflammatory markers used to monitor disease activity in systemic vasculitis circulating endothelial cells seem to be a promising new marker of this systemic disorder.

\section{References}

Ahn, Y.; Kim, Y.S. \& Jeong, M.H. (2006). The role of nuclear factor kappa B activation in atherosclerosis and ischemic cardiac injury. Korean Circulation J, Vol.36, pp. 245-251, ISSN 1738-5520

Bach, F.H.; Hancock W.W. \& Ferran, C. (1997). Protective genes expressed in endothelial cells: a regulatory response to injury. Immunology today, Vol.18, No.10, pp. 483-486, ISSN 0167 -5699

Baldwin, A. S. (1996). The NF-[kappa]B-[alpha] proteins: new discoveries and insights, Ann Rev Immunol, Vol.14, pp. 649-681, ISSN 0732-0582

Berghe, W. V.; Plaisance, S.; Boone, E.; De Bosscher, K.; Schmitz, M. L.; Fiers, W. \& Haegeman, G. (1998). p38 and extracellular signal-regulated kinase mitogenactivated protein kinase pathways are required for nuclear factor-[kappa]B p65 transactivation mediated by tumor necrosis factor. J Biol Chem, Vol.273, pp. 32853290, ISSN 0021-9258

Bevilacqua, M.P. \& Nelson, R.M. (1993). Selectins. J Clin Invest, Vol.91, pp. 379-387, ISSN 0021-9738

Bogdan, C.; Vodovotz, Y.; Paik, J.; Xie, Q.W. \& Nathan, C. (1991). Mechanism of suppression of nitric oxide synthase expression by interleukin-4 in primary mouse macrophages. J Leuk Biol, Vol.55, pp. 227- 233, ISSN 0741-5400

Bogle, R.G.; Macallister, R.J.; Whitley, G.S.J. \& Vallance, P. (1995). Induction of NGmonomethyl-L-arginine uptake: a mechanism for differential inhibition of NO synthases? Am J Physiol Cell Physiol, Vol.269, pp. C750-756, ISSN 0363-6143

Brady, R.H. (1994). Leukocyte adhesion molecules and kidney diseases. Kidney Int, Vol.45, pp. 1285-1300, ISSN 0085-2538

Brand, K.; Page, S.; Walli, A.K.; Neumerier, D. \& Baeuerle, P.A. (1997). Impared endothelial function and smooth muscle cell function in oxidative stress: role of nuclear factor[kappa]B in atherogenesis. Exp Physiol, Vol.82, pp. 297-304, ISSN 0958-0670

Brandes, R.P. \& Kreuzer, J. (2005). Vascular NADPH oxidases: molecular mechanisms of activation. Cardiovasc Res, Vol.65, pp. 16-27, ISSN 0008-6363

Brown, K.; Gerstberger, S.; Carlson, L.; Franzoso, G. \& Siebenlist, U. (1995). Control of [kappa]B-[alpha] proteolysis by sitespecific, signal-induced phosphorylation. Science, Vol.267, pp. 1485-1488, ISSN 0036-8075

Bruegger, D.; Rehm, M.; Abicht, J.; Paul, J.O.; Stoeckelhuber, M.; Pfirrmann, M.; Reichart, B.; Becker, B.F. \& Christ, F. (2009). Shedding of the endothelial glycocalyx during cardiac surgery: on-pump versus off-pump coronary artery bypass graft surgery. $J$ Thorac Cardiovasc Surg, Vol.138, pp. 1445-1447, ISSN 0022-5223

Bucci, M.; Gratton, J.P. \& Rudic, R.D. (2000). In vivo delivery of the caveolin-1 scaffolding domain inhibits nitric oxide synthesis and reduces inflammation. Nature Med, Vol.6, pp. 1362-1367, ISSN 1078-8956 
Cai, H. \& Harrison, D. G. (2000). Endothelial dysfunction in cardiovascular diseases: the role of oxidant stress. Circ Res, Vol.87, pp. 840-844, ISSN 0009-7330

Calara, F.; Dimayuga, P.; Neimann, A.; Thyberg, J.; Diczfalusy, U. \& Witztum J.L. (1998). Regnstrom: an animal model to study local oxidation of LDL and its biological effects in the arterial wall. Arterioscler Thromb Vasc Biol, Vol.18, pp. 884-893, ISSN 1079-5642

Chen, J.X. \& Stinnett, A. (2008). Disruption of Ang-1/Tie-2 signaling contributes to the impaired myocardial vascular maturation and angiogenesis in type II diabetic mice. Arterioscler Thromb Vasc Biol, Vol.28, pp. 1606-1613, ISSN $1079-5642$

Chen, X.L.; Varner, S.E.; Rao, A.S.; Grey, J.Y.; Thomas, S.; Cook, C.K.; Wasserman, M.A.; Medford, R.M.; Jaiswal, A.K. \& Kunsch, C. (2003). Laminar flow induction of antioxidant response element-mediated genes in endothelial cells. A novel antiinflammatory mechanism. J Biol Chem, Vol.278, pp. 703-711, ISSN 0021-9258

Chiba, R.; Nakagawa, N.; Kurasawa, K.; Tanaka, Y.; Saito, Y. \& Iwamoto, I. (1999). Ligation of CD31 (PECAM-1) on endothelial cells increases adhesive function of avß3 integrin and enhances $B 1$ integrin-mediated adhesion of eosinophils to endothelial cells. Blood, Vol.94, pp. 1319-1329, ISSN 0006-4971

Choi, H.K.; Lamprecht, P.; Niles, J.L.; Gross, W.L. \& Merkel, P.A. (2000). Subacute bacterial endocarditis with positive cytoplasmic antineutrophil cytoplasmic antibodies and anti-proteinase 3 antibodies. Arthritis Rheum, Vol.43, pp. 226-231, ISSN 1529-0131

Choi, K.; Kennedy, M.; Kazarov, A.; Papadimitriou, J.C.; Keller, G.A. (1998). A common precursor for hematopoietic and endothelial cells. Development, Vol.125, pp. 725732, ISSN 1011-6370

Cid, M.C. (2002). Endothelial cell biology, perivascular inflammation, and vasculitis. Clev Clin J Med, Vol.69, Suppl 2, pp. S1145-1149, ISSN 0891-1150

Cid, M.C.; Cebrián, M.; Font, C.; Coll-Vinent, B.; Hernández-Rodríguez, J.; Esparza, J.; Urbano-Márquez, A. \& Grau, J. M . (2000). Cell adhesion molecules in the development of inflammatory infiltrates in giant-cell arteritis.Inflammationinduced angiogenesis as the preferential site of leukocyte-endothelial cell interactions. Arthritis Rheum, Vol.43, pp. 184-194, ISSN 1529-0131

Cid, M.C.; Coll-Vinent, B. \& Bielsa, I. (2002). Endothelial cell adhesion molecules. In: Inflammatory Diseases of Blood Vessels, G.S. Hoffman, \& C.M. Weyand, (Ed.), 13-28, Marcel Dekker, ISBN 978-082-4702-69-4

Cid, M.C.; Segarra, M.; García-Martínez, A. \& Hernández-Rodríguez, J. (2004). Endothelial cells, antineutrophil cytoplasmic antibodies, and cytokines in the pathogenesis of systemic vasculitis. Curr Rheumatol Rep, Vol.6, No.3, pp. 184-194, ISSN 1523-3774

Coll-Vinent, B.; Cebrián, M.; Cid, M.C.; Font, C.; Esparza, J. \& Juan, M. (1998). Dynamic pattern of endothelial cell adhesion molecule expression in muscle and perineural vessels from patients with classical polyarteritis nodosa. Arthritis Rheum, Vol.41, pp. 435-444, ISSN 1529-0131

Cook-Mills, J.M. \& Deem, T.L. (2005). Active participation of endothelial cells in inflammation. J Leukocyte Biol, Vol.77, pp. 487-495, ISSN 0741-5400

Crabtree, M.J.; Tatham, A.L.; Hale, A.B.; Alp, N.J. \& Channon, K.M. (2009). Critical role for tetrahydrofolate reductase in regulation of endothelial nitric-oxide synthase coupling: relative importance of the de novo biopterin synthesis versus salvage pathways. J Biol Chem, Vol.284, pp. 28128-28136, ISSN 0021-9258 
Deem, T.L. \& Cook-Mills, J.M. (2004). Vascular cell adhesion molecule-1 (VCAM-1) activation of endothelial cell matrix metalloproteinases: role of reactive oxygen species. Blood, Vol.104, pp. 2385-2393, ISSN 0006-4971

Dekker, R.J.; Soest, S.; Fontijn, R.D.; Salamanca, S.; Groot, P.; VanBavel, E.; Pannekoek, H. \& Horrevoets, A. (2002). Prolonged fluid shear stress induces a distinct set of endothelial cell genes, most specifically lung Krüppel-like factor (KLF2). Blood, Vol.100, pp. 1689-1698, ISSN 0006-4971

Del Papa, N.; Guidalhi, L.; Sironi, M.; Shoenfeld, Y.; Mantovani, A. \& Tincani, A. (1996). Anti-endothelial cell IgG antibodies from patients with Wegener's granulomatosis bind to human endothelial cells in vitro and induce adhesion molecule expression and cytokine secretion. Arthritis Rheum, Vol.39, pp. 758-766, ISSN 1529-0131

DeLeo, F.R. \& Quinn, M.T. (1996). Assembly of the phagocyte NADPH oxidase: molecular interaction of oxidase proteins. J Leukoc Biol, Vol.60, pp. 677-691, ISSN 0741-5400

Díaz-Flores, L.; Gutiérrez, R.; Madrid, J.F.; Varela, H.; Valladares, F.; Acosta, E.; MartínVasallo, P.; Díaz-Flores, L. (2009). Pericytes. Morphofunction, interactions and pathology in a quiescent and activated mesenchymal cell niche. Histol Histopathol, Vol.24, pp. 909-969, ISSN 0213-3911

Dignat-George, F. \& Sampol J. (2000). Circulating endothelial cells in vascular disorders: new insights into an old concept. Eur J Haematol, Vol.65, pp. 215-220, ISSN 09024441

Djordjević, B.V.; Stanković, T.; Ćosić, V.; Zvezdanović, L.; Kamenov, B.; Tasić-Dimov, D. \& Stojanović, I. (2004). Immune system-mediated endothelial damage is associated with NO and antioxidant system disorders. Clin Chem Lab Med, Vol.42, No.10, pp. 1117 - 1121, ISSN 1434-6621

Djordjević, B.V.; Stojanović, I.; Ćosić, V.; Zvezdanović, L.; Deljanin-Ilić, M.; Dimić, S.; Kundalić, B.; Cvetković, T. \& Jevtović-Stoimenov T. (2008). Serum neopterin, nitric oxide, inducible nitric oxide synthase and tumor necrosis factor-a levels in patients with ischemic heart disease. Clin Chem Lab Med, Vol.46, No.8, pp. 1149-1155, ISSN 1434-6621

Dorseuil, O.; Quinn, M.T. \& Bokoch, G.M. (1995). Dissociation of Rac translocation from p47phox/p67phox movements in human neutrophils by tyrosine kinase inhibitors J Leukoc Biol, Vol.58, pp. 108-113, ISSN 0741-5400

Duperray, A.; Languino, L.R.; Plescia, J.; McDowall, A.; Hogg, N.; Craig, A.G.; Berendt, A.R. \& Altieri, D.C. (1997). Molecular identification of a novel fibrinogen binding site on the first domain of ICAM-1 regulating leukocyte-endothelium bridging. J Biol Chem, Vol.272, pp. 435-441, ISSN 0021-9258

Endemann, D. \& Schiffrin E. (2004). Endothelial dysfunction. J Am Soc Nephrol, Vol.15, pp. 1983-1992, ISSN 1046-6673

Etienne-Manneville, S.; Manneville, J.B.; Adamson, P.; Wilbourn, B.; Greenwood, J. \& Couraud, P.O. (2000). ICAM-1-coupled cytoskeletal rearrangements and transendothelial lymphocyte migration involve intracellular calcium signaling in brain endothelial cell lines. J Immunol, Vol. 165, pp. 3375-3383, ISSN 0022-1767

Falk, R.J. \& Jennette J.C. (1988). Anti-neutrophil cytoplasmatic autoantibodies with specificity for myeloperoxidase in patients with systemic vasculitis and idiopathic necrotizing and crescentic glomerulonephritis. N Engl J Med, Vol. 318, pp. 16511657, ISSN 0028-4793 
Falk, R.J.; Terell, R.S.; Charles, R.A. \& Jennette J.C. (1990). Anti-neutrophil cytoplasmic autoantibodies induce neutrophils to degranulate and produce oxygen radicals in vitro. Proc Natl Acad Sci USA, Vol.87, pp. 4115-4119, ISSN 0027-8424

Finkel T. (2003). Oxidant signals and oxidative stress. Curr Opin Cell Biol, Vol. 15, pp. 247254, ISSN 1369-5266

Fitzgerald, M.L.; Wang, Z.; Park, P.W.; Murphy, G. \& Bernfield, M. (2000). Shedding of syndecan-1 and -4 ectodomains is regulated by multiple signaling pathways and mediated by a TIMP-3-sensitive metalloproteinase. J Cell Biol, Vol.148, pp. 811-824, ISSN 1540-8140

Fledderus, J.O.; Boon, R.A.; Volger, O.L.; Hurttila, H.; Ylä-Herttuala, S.; Pannekoek, H.; Levonen, A.L. \& Horrevoets, A.J. (2008). KLF2 primes the antioxidant transcription factor Nrf2 for activation in endothelial cells. Arterioscler Thromb Vasc Biol, Vol.28, pp. 1339-1346, ISSN 1079-5642

Flint, J.; Morgan, M.D. \& Savage, C.O.S. ((2010). Pathogenesis of ANCA-associated vasculitis. Rheum Dis Clin North Am, Vol.36, No.3, pp. 463-477, ISSN 1558-3163

Flores-Suarez, L.F.; Cabiedes, J.; Villa, A.R.; van der Woude, F.J. \& Alcocer-Varela, J. (2003). Prevalence of antineutrophil cytoplasmic autoantibodies in patients with tuberculosis. Rheumatology (Oxford), Vol.42, pp. 223-229, ISSN 1462-0324

Foreman, K.E.; Vaporciyan, A.A.; Bonish, B.K.; Jones, M.L.; Johnson, K.J.; Glovsky, M.M.; Eddy, S.M. \& Ward P.A. (1994). C5a-induced expression of P-selectin in endothelial cells. J Clin Invest, Vol.94, pp. 1147-1155, ISSN 0021-9738

Fujimoto T. (1993). Calcium pump of the plasma membrane is localized in caveolae. J Cell Biol, Vol.120, pp. 1147-1157, ISSN 1540-8140

Gaengel, K.; Genové, G.; Armulik, A. \& Betsholtz, C. (2009). Endothelial-mural cell signaling in vascular development and angiogenesis. Arterioscler Thromb Vasc Biol, Vol.29, pp. 630-638, ISSN 1079-5642

Galley, H. \& Webster, N. (2004). Physiology of the endothelium. Brit J Anaesth, Vol.93, pp. 105-113, ISSN 0007-0912

Garcia-Cardena, G.; Martasek, P.; Masters, B.S.S.; Skidd, P.M.; Couet, J.; Li, S; Lisanti, M.P. \& Sessa, W. (1997). Dissecting the interaction between nitric oxide synthase (NOS) and caveolin. Functional significance of the NOS caveolin binding domain in vivo. J Biol Chem, Vol.272, pp. 25437- 25440, ISSN 0021-9258

Groemping, Y. \& Rittinger, K. (2005). Activation and assembly of the NADPH oxidase: a structural perspective. Biochem J, Vol.386, pp. 401-416, ISSN 0264-6021

Harrison, D.G. (1997). Cellular and molecular mechanisms of endothelial cell dysfunction. J Clin Invest, Vol.100, pp. 2153-2157, ISSN 0021-9738

Haubitz, M. \& Woywodt A. (2004). Circulating endothelial cells and vasculitis. Intern Med, Vol.43, No.8, pp. 660-667, ISSN 0918-2918

Heeringa, P.; Schreiber, A.; Falk, R.J. \& Jennette, J.C. (2004). Pathogenesis of pulmonary vasculitis. Semin Respir Crit Care Med, Vol.25, No.5, pp. 465-474, ISSN 1069-3424

Heiska, L.; Alfthan, K.; Gronholm, M.; Vilja, P.; Vaheri, A. \& Carpen, O. (1998). Association of ezrin with intercellular adhesion molecule-1 and -2 (ICAM-1 and ICAM-2). Regulation by phosphatidylinositol 4, 5-bisphosphate. J Biol Chem, Vol.273, pp. 21893-21900, ISSN 0021-9258

Herren, B.; Levkau, B.; Raines, E.W. \& Ross, R. (1998). Cleavage of B-catenin and plakoglobin and shedding of VE-cadherin during endothelial apoptosis: evidence 
for a role for caspases and metalloproteinases. Mol Biol Cell, Vol.9, pp. 1589-1601, ISSN 1059-1524

Hojo, Y.; Saito, Y.; Tanimoto, T.; Hoefen, R.; Baines, C.; Yamamoto, K.; Haendeler, J.; Asmis, R. \& Berk, B. (2002). Fluid shear stress attenuates hydrogen peroxide-induced c-Jun NH2-terminal kinase activation via a glutathione reductase-mediated mechanism. Circ Res, Vol.91, pp. 712-718, ISSN 0009-7330

Igarashi, J.; Thatte, H.S.; Prabhakar, P.; Golan, D.E. \& Michel T. (1999). Calcium-independent activation of endothelial nitric oxide synthase by ceramide. Proc Natl Acad Sci USA, Vol.96, pp. 12583-12588, ISSN 0027-8424

Jackson, D.E.; Ward, C.M.; Wang, R. \& Newman, P.J. (1997). The protein-tyrosine phosphatase SHP-2 binds platelet/endothelial cell adhesion molecule-1 (PECAM-1) and forms a distinct signaling complex during platelet aggregation. Evidence for a mechanistic link between PECAM-1- and integrin-mediated cellular signaling. J Biol Chem, Vol.272, pp. 6986-6993, ISSN 0021-9258

Jamin, C.; Dugue, C.; Alard, J.E.; Jousse, S.; Saraux, A.; Guillevin, L.; Piette, J.C. \& Youinou P. (2005). Induction of endothelial cell apoptosis by the binding of anti-endothelial cell antibodies to Hsp60 in vasculitis-associated systemic autoimmune diseases. Arthritis Rheum, Vol.52, pp. 4028 -4038, ISSN 1529-0131

Jennette, J.C.; Hoidai, J.R. \& Falk R.J. (1990). Specificity of anti-neutrophil cytoplasmatic autoantibodies for proteinase 3. Blood, Vol.75, pp. 2263-2264, ISSN 0006-4971

Kissel, J.T.; Riethman, J.L.; Omerza, J.; Rammohan, K.W. \& Mendell J.R. (1989). Peripheral nerve vasculitis: immune characterization of the vascular lesions. Ann Neurol, Vol.25, pp. 291-297, ISSN 0364-5134

Kopp, E. \& Ghosh S. (1994). Inhibition of NF-[kappa]B by sodium salicylate and aspirin. Science, Vol.265, pp. 956-959, ISSN 0036-8075

Kraft, A.D.; Johnson, D.A. \& Johnson, J.A. (2004). Nuclear factor E2-related factor 2dependent antioxidant response element activation by tert-butylhydroquinone and sulforaphane occurring preferentially in astrocytes conditions neurons against oxidative insult. J Neurosci, Vol.24, pp. 1101-1112, ISSN 0270-6474

Lee, T.J. \& Yu, J.G. (2002). L-Citrulline recycle for synthesis of NO in cerebral perivascular nerves and endothelial cells. Ann NY Acad Sci, Vol.962, pp. 73-80, ISSN 0077-8923

Li, J.M.; Fan, L.M.; Christie, M.R. \& Shah, A.M. (2005). Acute tumor necrosis factor alpha signaling via NADPH oxidase in microvascular endothelial cells: role of p47phox phosphorylation and binding to TRAF4. Mol Cell Biol, Vol.25, pp. 2320-2330, ISSN 1471-0072

Mamdouh, Z.; Chen, X.; Pierini, LM.; Maxfield, F.R. \& Muller, W.A. (2003). Targeted recycling of PECAM from endothelial surface-connected compartments during diapedesis. Nature, Vol.421, pp. 748-753, ISSN 1078-8956

Mandell, B.F. \& Calabrese L.H. (1998). Infections and systemic vasculitis. Curr Opin Rheumatol, Vol.10, pp. 51-57, ISSN 1040-8711

Mann, G.E.; Yudilevich, D.L. \& Sobrevia, L. (2003). Regulation of amino acid and glucose transporters in endothelial and smooth muscle cells. Physiol Rev, Vol.83, pp. 183252, ISSN 0031-9333

Mannick J.B. (2007). Regulation og apoptosis by protein S-nitrosylation. Amino Acids, Vol.32, pp. 523-526, ISSN 0939-4451 
Mantovani, A.; Bussolino, F. \& Introna M. (1997). Cytokine regulation of endothelial cell function: from molecular level to the bedside. Immunol Today, Vol.18, pp. 231- 240, ISSN $0167-5699$

Matheny, H.E.; Deem, T.L. \& Cook-Mills, J.M. (2000). Lymphocyte migration through monolayers of endothelial cell lines involves VCAM-1 signaling via endothelial cell NADPH oxidase J Immunol, Vol.164, pp. 6550-6559, ISSN 0022-1767

Michel, J.B.; Feron, O.; Sacks, D. \& Michel T. (1997). Reciprocal regulation of endothelial nitric-oxide synthase by Ca2+-calmodulin and caveolin. J Biol Chem, Vol.272, pp. 15583- 15586, ISSN 0021-9258

Mulivor, A.W. \& Lipowsky, H.H. (2004). Inflammation- and ischemia-induced shedding of venular glycocalyx. Am J Physiol Heart Circ Physiol, Vol.286, pp. H1672-H1680, ISSN 0363-6135

Murphy, G.; Willenbrock, F.; Crabbe, T.; O'Shea, M.; Ward, R.; Atkinson, S.; O'Connell, J. \& Docherty, A. (1994). Regulation of matrix metalloproteinase activity. Ann N Y Acad Sci, Vol.732, pp. 31-41, ISSN 0077-8923

Nara, H.; Okamoto, H.; Minota, S. \& Yoshio, T. (2006). Mouse monoclonal anti-human thrombomodulin antibodies bind to and activate endothelial cells through NFkappaB activation in vitro. Arthritis Rheum, Vol.54, pp. 1629 -1637, ISSN 1529-0131

Palmer, R.M.J.; Ashton, D.S. \& Moncada, S. (1988). Vascular endothelial cells synthesize nitric oxide from L-arginine. Nature, Vol.333, pp. 664 - 666, ISSN 1078-8956

Patey, N.; Lesavre, P; Halbwachs-Mecarelli, L. \& Noel L.H. (1996). Adhesion molecules in human crescentic glomerulonephritis. J Pathol, Vol.179, pp. 414-420, ISSN 0022-3417

Pellegatta, F.; Chierchia, S.L. \& Zocchi, M.R. (1998). Functional association of platelet endothelial cell adhesion molecule-1 and phosphoinositide 3-kinase in human neutrophils J Biol Chem, Vol.273, pp. 27768-27771, ISSN 0021-9258

Peng, H.B.; Libby, P. \& Liao, J.K. (1995). Induction and stabilization of I kappa B alpha by nitric oxide mediates inhibition of NF-kappa B. J Biol Chem, Vol.270, pp. 1421414219, ISSN 0021-9258

Porges, A.J.; Redecha, P.B. \& Kimberly, W.T. (1994). Anti-neutrophil cytoplasmic antibodies engage and activate human neutrophils via Fc-RIIa. J Immunol, Vol.153, pp. 12711280, ISSN 0022-1767

Praprotnik, S.; Blank, M.; Meroni, P.L.; Rozman, B.; Eldor, A. \& Shoenfeld Y. (2001). Classification of anti-endothelial cell antibodies into antibodies against microvascular and macrovascular endothelial cells: the pathogenic and diagnostic implications. Arthritis Rheum, Vol.44, pp. 1484-1494, ISSN 1529-0131

Pumphrey, N.J.; Taylor, V.; Freeman, S.; Douglas, M.R.; Bradfield, P.F.; Young, S.P.; Lord, J.M.; Wakelam, M.J.; Bird, I.N.; Salmon, M. \& Buckley, CD. (1999). Differential association of cytoplasmic signalling molecules SHP-1, SHP-2, SHIP and phospholipase C- $\gamma 1$ with PECAM-1/CD31. FEBS Lett, Vol.450, pp. 77-83, ISSN 0014-5793

Rabelink, T.J. \& Luscher, T.F. (2006). Endothelial nitric oxide synthase: host defense enzyme of the endothelium? Arterioscler Thromb Vasc Biol, Vol.26, pp. 267-271, ISSN 10795642

Radford, D.J.; Savage, C.O. \& Nash G.B. (2000). Treatment of rolling neutrophils with antineutrophil cytoplasmic antibodies causes conversion to firm integrin-mediated adhesion. Arthritis Rheum, Vol.43, pp. 1337-1345, ISSN 1529-0131 
Raines, E. \& Ferri N. (2005). Cytokines affecting endothelial and smooth cells in vascular disease. J Lipid Res, Vol.46, pp. 1081-1092, ISSN 0022-2275

Rastaldi, M.P.; Ferrario, F.; Tunesi, S.; Yang, L. \& d'Amico G. (1996). Intraglomerular and interstitial leukocyte infiltration, adhesion molecules, and interleukin-1 alpha expression in 15 cases of anti-neutrophil cytoplasmic autoantibody-associated renal vasculitis. Am J Kidney Dis, Vol.27, pp. 48-57, ISSN 0272-6386

Rattan, V.; Sultana, C.; Shen, Y. \& Kalra, V.K. (1997). Oxidant stress-induced transendothelial migration of monocytes is linked to phosphorylation of PECAM-1. Am J Physiol, Vol.273, pp. E453-E461, ISSN 0885-8276

Ray, R. \& Shah, A.M. (2005). NADPH oxidase and endothelial cell function. Clin Sci, Vol.109, pp. 217-226, ISSN 0143-5221

Read, M.A.; Whitley, M.Z.; Williams, A.J. \& Collins T. (1994). NF-кB and IкBa: An inducible regulatory system in endothelial activation. J Exp Med, Vol.179, pp. 503-512, ISSN 1540-9538

Roebuck, K.A. \& Finnegan, A. (1999). Regulation of intercellular adhesion molecule-1 (CD54) gene expression J Leukoc Biol, Vol.66, pp. 876-888, ISSN 0741-5400

Ryter, S.W.; Alam, J. \& Choi, A.M. (2006). Heme oxygenase-1/carbon monoxide: from basic science to therapeutic applications. Physiol Rev, Vol.86, pp. 583-650, ISSN 0031-9333

Sais, G.; Vidaller, A.; Jugcla, A.; Condom, E. \& Peyri J. (1997). Adhesion molecule expression and endothelial cell activation in cutaneous leukocytoclastic vasculitis: an immunohistologic and clinical study in 42 patients. Arch Dermatol, Vol. 133, pp. 443450, ISSN 0003-987X

Sano, H.; Nakagawa, N.; Chiba, R.; Kurasawa, K.; Saito, Y. \& Iwamoto, I. (1998). Crosslinking of intercellular adhesion molecule-1 induces interleukin-8 and RANTES production through the activation of MAP kinases in human vascular endothelial cells. Biochem Biophys Res Commun, Vol.250, pp. 694-698, ISSN 0006-291X

Savage, C.; \& Williams, J. (2007). Anti-Endothelial Cell Antibodies in Vasculitis. J Am Soc Nephrol, Vol.18, pp. 2424-2426, ISSN 1046-6673

Sawada, N.; Murata, M. \& Kikuchi K. (2003). Tight junctions and human diseases. Med Electron Microsc, Vol.36, pp. 147-156, ISSN 1437-773X

Schenkel, A.R.; Mamdouh, Z.; Chen, X.; Liebman, R.M. \& Muller, W.A. (2002). CD99 plays a major role in the migration of monocytes through endothelial junctions. Nat Immunol, Vol.3, pp. 143-150, ISSN : 1529-2908

Shaw, S.K.; Perkins, B.N.; Lim, Y.C.; Liu, Y.; Nusrat, A.; Schnell, F.J.; Parkos, C.A. \& Luscinskas, F.W. (2001). Reduced expression of junctional adhesion molecule and platelet/endothelial cell adhesion molecule-1 (CD31) at human vascular endothelial junctions by cytokines tumor necrosis factor- $\alpha$ plus interferon- $\gamma$ does not reduce leukocyte transmigration under flow. Am J Pathol, Vol.159, pp. 22812291, ISSN 0887-8005

Smith, J.D.; Lawson, C.; Yacoub, M.H. \& Rose, M.L. (2000). Activation of NF-kappa B in human endothelial cells induced by monoclonal and allospecific HLA antibodies. Int Immunol, Vol.12, pp. 563 -571, ISSN 0953-8178

Steiner, L.; Kroncke, K.; Fehsel, K. \& Kolb-Bachofen V. (1997). Endothelial cells as cytotoxic effector cells: cytokine-activated rat islet endothelial cells lyse syngeneic islet cells via nitric oxide. Diabetologia, Vol.40, pp. 2150-2155, ISSN 0012-186X

Tarbell, J.M. \& Ebong, E.E. (2008). The endothelial glycocalyx: a mechano-sensor and transducer. Sci Signal 1, pt8, ISSN 1945-0877 
Thannickal, V.J. \& Fanburg, BL. (2000). Reactive oxygen species in cell signaling. Am J Physiol Lung Cell Mol Physiol, Vol.279, pp. L1005-L1028, ISSN 1040-0605

Thurberg, B.L. \& Collins, T. (1998). The nuclear factor-kappa B/inhibitor of kappa B autoregulatory system and atherosclerosis. Curr Opin Lipidol, Vol.9, pp. 387-396, ISSN 0957-9672.

Toyoda, M.; Petrosian, A. \& Jordan S.C. (1999). Immunological characterisation of antiendothelial cell antibodies induced by cytomegalovirus infection. Transplantation, Vol.68, pp. 1311 -1318, ISSN 0931-0509

Tse, W.Y.; Williams, J.; Pall, A.; Wilkes, M.; Savage, C.O. \& Adu, D. (2001). Antineutrophil cytoplasmic antibody-induced neutrophil nitric oxide production is nitric oxide synthase independent. Kidney Int, Vol.9, pp. 593-600, ISSN 0085-2538

Tudor, S.; Hess, K.L. \& Cook-Mills, J.M. (2001). Cytokines modulate endothelial cell intracellular signal transduction required for VCAM-1-dependent lymphocyte transendothelial migration Cytokine, Vol.15, pp. 196-211, ISSN 1043-4666

Van Wart, H.E. \& Birkedal-Hansen, H. (1990). The cysteine switch: a principle of regulation of metalloproteinase activity with potential applicability to the entire matrix metalloproteinase gene family. Proc Natl Acad Sci, USA, Vol.87, pp. 5578-5582, ISSN 0027-8424

Wang, J.B.; Guan, J.; Shen, J.; Zhou, L.; Zhang, Y.J.; Si, Y.F.; Yang, L.; Jian, X.H. \& Sheng Y. (2009). Insulin increases shedding of syndecan-1 in the serum of patients with type 2 diabetes mellitus. Diabetes Res Clin Pract, Vol.86, pp. 83-88, ISSN 0168-8227

Wang, Q. \& Doerschuk, C.M. (2001). The p38 mitogen-activated protein kinase mediates cytoskeletal remodeling in pulmonary microvascular endothelial cells upon intracellular adhesion molecule-1 ligation J Immunol, Vol.166, pp. 6877-6884, ISSN 0022-1767

Weinbaum, S.; Tarbell, J.M. \& Damiano, E.R. (2007). The structure and function of the endothelial glycocalyx layer. Annu Rev Biomed Eng, Vol.9, pp. 121-167, ISSN 15239829

Weiner, C.P.; Lizasoain, I.; Baylis, S.A.; Knowles, R.C.; Charles, I.C. \& Moncada S. (1994). Induction of calcium-dependent nitric oxide synthase by sex hormones. Proc Natl Acad Sci USA, Vol.91: pp. 5212- 5216, ISSN 0027-8424

Xia, Y; Tsai, A; Berka, V. \& Zweier J.L. (1998). Superoxide generation from endothelial nitric oxide synthase. A Ca2+/calmodulin-dependent and tetrahydrobiopterin regulatory process. J Biol Chem, Vol.273, pp. 25804-25808, ISSN 0021-9258

Yang, J.J; Preston, G. \& Pendergraft W. (2001). Internalization of proteinase 3 is concomitant with endothelial cell apoptosis and internalization of myeloperoxidase with generation of intracellular oxidants. Am J Pathol, Vol. 158, pp. 581-592, ISSN 08878005

Zhang, J.; DeFelice, A.F.; Hanig, J.P. \& Colatsky, T. (2010). Biomarkers of endothelial cell activation serve as potential surrogate markers for drug-induced vascular injury. Toxicol Pathol, Vol.38, No.6, (October 2010), pp. 856-871, ISSN 0192-6233

Zhong, H.; SuYang, H; Erdjument-Bromage, H; Tempst, P. \& Ghosh S. (1997). The transcriptional activity of NF-[kappa]B is regulated by the I[kappa]B-associated PKAc subunit through a cyclic AMP-independent mechanism. Cell, Vol.89, pp. 413424, ISSN 0092-8674 


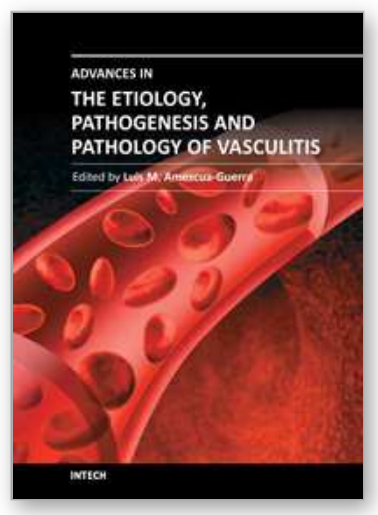

\author{
Advances in the Etiology, Pathogenesis and Pathology of \\ Vasculitis \\ Edited by Dr. Luis M Amezcua-Guerra
}

ISBN 978-953-307-651-5

Hard cover, 438 pages

Publisher InTech

Published online 17, October, 2011

Published in print edition October, 2011

This book represents the culmination of the efforts of a group of outstanding experts in vasculitis from all over the world, who have endeavored to devote their work to this book by keeping both the text and the accompanying figures and tables lucid and memorable. Here, you will find an amalgam between evidencebased medicine to one based on eminence, through an exciting combination of original contributions, structured reviews, overviews, state-of the-art articles, and even the proposal of novel pathogenetic models of disease. The book contains contributions on the etiology and pathology of vasculitis, the potential role of endothelial cells and cytokines in vascular damage and repair as well as summaries of the latest information on several primary and secondary vasculitis syndromes. It also covers selected topics such as organ-specific vasculitic involvement and quality of life issues in vasculitis. The editor and each of the authors invite you to share this journey through one of the most exciting fields of the medicine, the world of Vasculitis.

\title{
How to reference
}

In order to correctly reference this scholarly work, feel free to copy and paste the following:

Vidosava B. Djordjević, Vladan Cosić, Lilika Zvezdanović-Celebić, Vladimir V. Djordjević and Predrag Vlahovic (2011). Endothelial Cells and Vasculitis, Advances in the Etiology, Pathogenesis and Pathology of Vasculitis, Dr. Luis M Amezcua-Guerra (Ed.), ISBN: 978-953-307-651-5, InTech, Available from:

http://www.intechopen.com/books/advances-in-the-etiology-pathogenesis-and-pathology-ofvasculitis/endothelial-cells-and-vasculitis

\section{INTECH}

open science | open minds

\section{InTech Europe}

University Campus STeP Ri

Slavka Krautzeka 83/A

51000 Rijeka, Croatia

Phone: +385 (51) 770447

Fax: +385 (51) 686166

www.intechopen.com

\section{InTech China}

Unit 405, Office Block, Hotel Equatorial Shanghai

No.65, Yan An Road (West), Shanghai, 200040, China

中国上海市延安西路65号上海国际贵都大饭店办公楼 405 单元

Phone: +86-21-62489820

Fax: $+86-21-62489821$ 
(C) 2011 The Author(s). Licensee IntechOpen. This is an open access article distributed under the terms of the Creative Commons Attribution 3.0 License, which permits unrestricted use, distribution, and reproduction in any medium, provided the original work is properly cited. 